\title{
Synergistic effects of seasonal deoxygenation and temperature truncate copepod vertical migration and distribution
}

\author{
James J. Pierson*, Wen-Cheng L. Slater, David Elliott, Michael R. Roman \\ Horn Point Laboratory, University of Maryland Center for Environmental Science, Cambridge, MD 21613, USA
}

\begin{abstract}
The vertical distribution of copepods in coastal and estuarine systems is altered by the concentration of dissolved oxygen in the water column. We studied the combined effects of temperature and dissolved oxygen on vertical distribution and migration behavior of the copepod Acartia tonsa in the Chesapeake Bay throughout the period of seasonal deoxygenation in 2010 and 2011. Vertically stratified net tows and hydrographic casts were conducted at 2 stations over diel cycles in spring, summer, and autumn. The partial pressure of dissolved oxygen $\left(\mathrm{pO}_{2}\right)$ was used as a metric for the condition of copepod habitat during each cruise instead of oxygen concentration, because partial pressure incorporates the temperature dependence of dissolved oxygen solubility, making it a more useful indication of available oxygen supply than concentration. Habitat conditions were described as having $\mathrm{pO}_{2}$ above limiting conditions, below the maximum respiratory demand but above potentially lethal conditions, or below the minimum basal respiratory demand. In general, adult males were found deeper in the water than females in most oxygen conditions. Regression tree analysis supported these findings and showed that $\mathrm{pO}_{2}$ was a key predictor of the fraction of copepodites, adult females, and adult males above the pycnocline, and for copepodites and adult females below the pycnocline. Temperature was a strong predictor of the fraction of adult males below the pycnocline, with a smaller fraction found there at higher temperatures. These findings suggest sex-specific responses to deoxygenation, potentially as a result of different oxygen demands or behavior.
\end{abstract}

KEY WORDS: Copepod - Hypoxia - Diel vertical migration - Vertical distribution · Acartia tonsa Chesapeake Bay · Estuarine

\section{INTRODUCTION}

The prevalence of deoxygenated water in coastal and estuarine systems is increasing worldwide, due largely to cultural eutrophication and other anthropogenic impacts in the coastal region (Diaz \& Rosenberg 2008, Rhein et al. 2013). In the Chesapeake Bay region, trends in deoxygenation have shown an increasing volume of hypoxic (dissolved oxygen < $2 \mathrm{mg} \mathrm{l}^{-1}$ ) and anoxic (dissolved oxygen $=0 \mathrm{mg} \mathrm{l}^{-1}$ ) bottom water over the past half-century (Hagy et al. 2004, Kemp et al. 2005), as well as an earlier onset of hypoxic conditions over this period (Murphy et al.

${ }^{*}$ Corresponding author: jpierson@umces.edu
2011). Water temperature is also increasing worldwide due to anthropogenic global warming (Rhein et al. 2013), with a rise of $0.021^{\circ} \mathrm{C} \mathrm{yr}^{-1}$ observed for the bottom water of the Chesapeake Bay (Preston 2004)

These increases in temperature and decreases in available oxygen alter the quality and quantity of habitat available to planktonic organisms found in the bottom water of the Chesapeake Bay. Dissolved oxygen availability to plankton is affected by temperature through changes in both the solubility of oxygen and the metabolic rate of the organisms; as temperature increases, solubility decreases while metabolic rate increases. Thus, with the current

() The authors 2017. Open Access under Creative Commons by Attribution Licence. Use, distribution and reproduction are unrestricted. Authors and original publication must be credited. 
observed trends of dissolved oxygen and temperature, demand is increasing as supply is decreasing (Deutsch et al. 2015). The combined effects of temperature and oxygen have been examined for openocean animals inhabiting oxygen minimum zones (Elder \& Seibel 2015, Seibel 2015, Seibel et al. 2016) and for fish in the Chesapeake Bay (Coutant 1985), but rarely have these 2 factors been considered together for zooplankton in seasonally deoxygenated coastal and estuarine systems.

In the Chesapeake Bay, the dominant copepod in the mesohaline portion is Acartia tonsa (Olson 1987), a calanoid copepod found in tropical and temperate estuaries worldwide (Mauchline 1998). Laboratory studies have shown the impact of low dissolved oxygen on A. tonsa reproduction (Roman et al. 1993, Stalder \& Marcus 1997, Sedlacek \& Marcus 2005), swimming speed (Decker et al. 2003), and feeding (Elliott et al. 2013b). Field studies have shown that under deoxygenated bottom water conditions, A. tonsa vertical distribution is in general shallower than when oxygen is normoxic in bottom water (Roman et al. 1993, Keister et al. 2000, Elliott et al. 2013a). However, in the presence of predators, this is not always the case (Taylor \& Rand 2003). Even while the vertical distribution may be skewed towards the surface under bottom water deoxygenation, some fraction of the population often occurs in that deeper water under all conditions (Roman et al. 1993, Taylor et al. 2007, Elliott et al. 2013a), which could be due to the use of bottom water as a refuge from fish predators, which require more oxygen than the copepods (Taylor et al. 2007). Diel vertical migration (DVM) behaviors are also altered by low oxygen water, with reduced amplitude of migration compared to fully oxygenated conditions (Roman et al. 1993, Keister et al. 2000, Pierson et al. 2009).

In all of these examples, temperature was not considered as an additional factor for the vertical distribution or migration behaviors. In an effort to incorporate the effects of temperature on dissolved oxygen supply and demand, Elliott et al. (2013a) determined the critical $\left(P_{\text {crit }}\right)$ and potentially lethal $\left(P_{\text {leth }}\right)$ partial pressure of oxygen for adult female $A$. tonsa, corresponding to the thresholds below which oxygen becomes limiting or lethal, respectively. These analyses were based largely on previous work on fishes and macro-invertebrates that incorporated oxygen and thermal stress (e.g. Pörtner 2010, Seibel 2011). A subsequent analysis showed that the fraction of individuals found below the pycnocline differed between fully oxygenated bottom water conditions and those where the bottom water was potentially lethal, but not between fully oxygenated and critical oxygen conditions (Elliott et al. 2013b). Further, no relationship was observed between the fraction of copepods below the pycnocline and the percent of the water below the pycnocline with lethal oxygen conditions for A. tonsa copepodites, while for nauplii, the mortality rate increased with the amount of lethal oxygen below the pycnocline (Elliott et al. 2013b), suggesting stage-specific responses to oxygen and to the severity of the deoxygenation.

The goal of this analysis is to determine the synergistic effects of temperature and dissolved oxygen on copepodites, adult female, and adult male A. tonsa vertical distribution and migration behavior in the Chesapeake Bay. We collected hydrographic data and conducted vertically stratified net tows at 2 stations in the Bay in spring, summer, and fall, to bracket the entire period of seasonal deoxygenation over 2 yr. The metrics of deoxygenation we used were derived from Elliott et al. (2013a,b), and our sampling strategy allowed us to encounter a range of temperature and oxygen conditions for comparison. These findings are presented in the context of habitat quality for A. tonsa in the Chesapeake Bay and the potentially changing climatic conditions that are likely to alter the available habitat.

\section{MATERIALS AND METHODS}

Three research cruises in each of 2 years (2010 and 2011) were conducted to study the abundance, vertical distribution, and diel migration of the copepod Acartia tonsa in relation to the dissolved oxygen habitat in the Chesapeake Bay. Deoxygenation generally begins in the northern portion of the Chesapeake Bay in the spring and spreads southward, reaching maximum volume in summer. This deoxygenated water then retreats from south to north in the autumn as the frequency of mixing events increases (e.g. Kemp et al. 2005). Cruises were scheduled to bracket the formation and dispersal of seasonally deoxygenated bottom water in the Chesapeake Bay, as well as the life histories of key copepod predators (Table 1). During spring cruises in May, temperatures were expected to be cooler than summer or autumn, and while some deoxygenated water was expected to be present, it was not expected to be as severe as summer. Summer cruises in July and August were expected to experience the most severe deoxygenation, with some instances of anoxic (sulfidic) conditions possible. The forage fish bay anchovy Anchoa mitchilli and gelatinous predators such as 
Table 1. Cruise information, including dates, stations occupied, number of MOCNESS tows completed at each station, and mean $( \pm \mathrm{SD})$ temperature, salinity, and dissolved oxygen concentration

\begin{tabular}{|lccccc|}
\hline Start date & Stn & $\begin{array}{c}\text { MOCNESS } \\
\text { tows }\end{array}$ & $\begin{array}{c}\text { Temperature } \\
\left({ }^{\circ} \mathrm{C}\right)\end{array}$ & Salinity & $\begin{array}{c}{\left[\mathrm{O}_{2}\right]} \\
\left(\mathrm{mg} \mathrm{l}^{-1}\right)\end{array}$ \\
\hline 24-31 May 2010 & North & 10 & $19.7(1.8)$ & $13.0(2.8)$ & $7.5(4.6)$ \\
& South & - & $19.3(1.2)$ & $17.7(3.1)$ & $8.3(2.4)$ \\
19-26 Aug 2010 & North & 5 & $27.2(0.5)$ & $16.4(2.5)$ & $4.8(3.2)$ \\
& South & 6 & $27.3(0.6)$ & $19.1(2.3)$ & $6.1(2.5)$ \\
21-27 Sep 2010 & North & - & $24.1(0.2)$ & $17.4(0.8)$ & $5.5(1.6)$ \\
& South & 6 & $23.8(0.2)$ & $20.8(1.1)$ & $5.6(0.8)$ \\
24-31 May 2011 & North & 3 & $20.7(3.0)$ & $8.4(3.9)$ & $6.1(4.7)$ \\
& South & 8 & $20.0(1.7)$ & $15.4(3.5)$ & $6.3(2.6)$ \\
19-26 Jul 2011 & North & 6 & $26.6(2.1)$ & $12.9(2.6)$ & $3.8(3.4)$ \\
& South & 6 & $26.0(0.9)$ & $16.8(2.3)$ & $2.6(2.5)$ \\
21-27 Sep 2011 & North & 6 & $23.2(0.6)$ & $11.0(3.3)$ & $4.6(2.7)$ \\
& South & 6 & $22.9(0.1)$ & $15.1(2.8)$ & $6.1(1.1)$ \\
& & & & & \\
\hline
\end{tabular}

below the pycnocline. Target depths were chosen based on dissolved oxygen data from the hydrographic cast that was conducted just prior to each net tow, but actual depths sampled were determined using data from the dissolved oxygen sensor on the MOCNESS. The pycnocline and oxycline were generally at the same depth, as has been reported previously for Chesapeake Bay (Pierson et al. 2009). For example, during a typical tow, the net was deployed slowly to within $2 \mathrm{~m}$ of the bottom depth, and the first sampling net was opened. The operator would note the surface mixed-layer oxygen concentration as well as the minimum oxygen concentration to determine sampling depths. the sea nettle Chrysaora quinquecirrha and the ctenophore Mnemiopsis leidyi were expected to be dominant copepod predators in summer. In autumn, temperatures were expected to be cooler than summer temperatures, and deoxygenated water was expected to be less severe than in summer. Predator abundances were expected to peak during this season. Station locations were chosen to provide contrasts within each season (Fig. 1). The North station $\left(38^{\circ} 31.32^{\prime} \mathrm{N}, 76^{\circ} 24.48^{\prime} \mathrm{W}\right)$ was selected because it was expected to experience more severe deoxygenation over a longer duration than the South station $\left(37^{\circ} 43.68^{\prime} \mathrm{N}, 76^{\circ} 12.0^{\prime} \mathrm{W}\right)$.

During each cruise, each station was occupied once for $2 \mathrm{~d}$, with the second day devoted to trawling. Hydrographic casts were conducted prior to each series of net tows with the shipboard Sea-Bird 911+ CTD and rosette system. Zooplankton net tows were then conducted with a $0.25 \mathrm{~m}^{2}$ MOCNESS net fitted with $200 \mu \mathrm{m}$ mesh nets and optional sensors to measure dissolved oxygen (Sea-Bird 43), chlorophyll a fluorescence and turbidity (WetLabs FLNTU), and photosynthetically active radiation ( $\left.\mathrm{PAR}_{i} \mathrm{Li}-\mathrm{Cor}\right)$. Here we present data from the MOCNESS nets and CTD casts. Repeated net tows were conducted over a $24 \mathrm{~h}$ period at each station to observe the DVM behavior of $A$. tonsa under the different conditions experienced throughout the project. The MOCNESS was towed in a stratified oblique pattern (Wiebe et al. 2015), with all samples collected from nets that were fished during the ascent of the net. Three depth intervals were sampled during each tow, corresponding to above the pycnocline, within the pycnocline, and

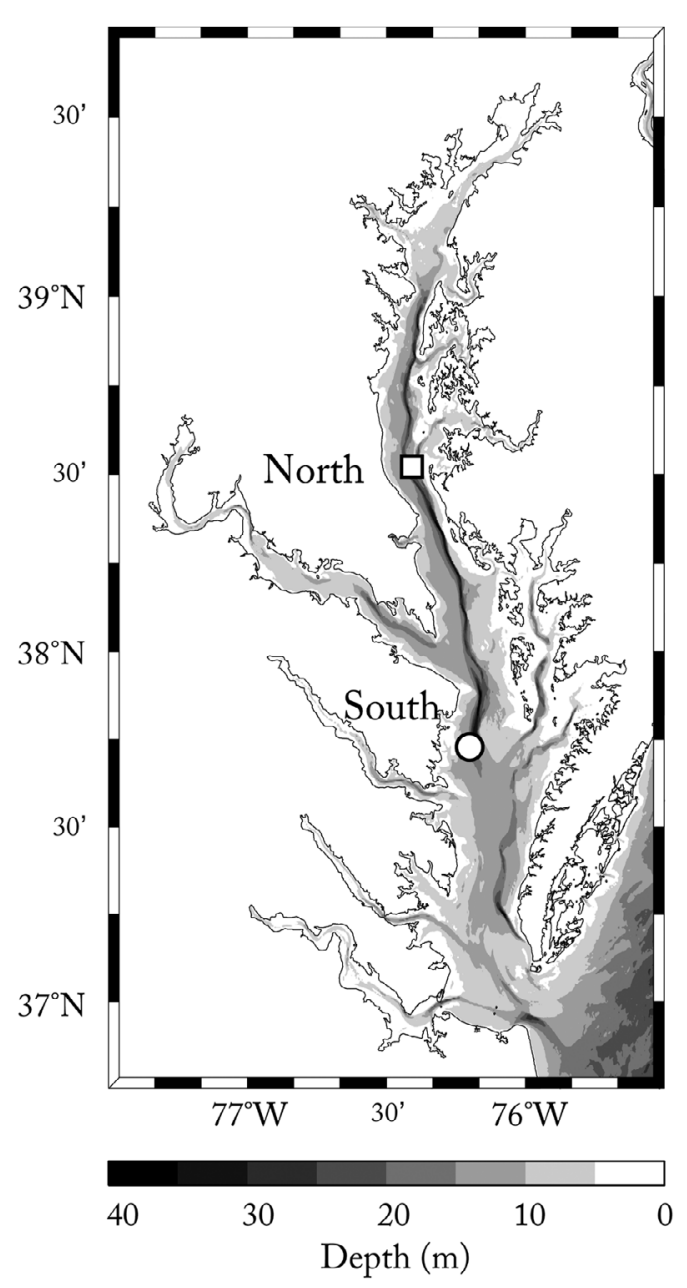

Fig. 1. Chesapeake Bay. Shading indicates bathymetry, and symbols indicate North (square) and South (circle) stations occupied during this project 
As the net was retrieved, the operator monitored the dissolved oxygen, and once it began to increase, the second net was opened, signifying the bottom of the pycnocline. Once the net reached the value observed by the operator for the upper mixed layer, the third net was opened and fished until the net reached the surface. The net was retrieved at a rate so that each net sampled a given layer for 2-3 min, corresponding to $30-50 \mathrm{~m}^{3}$ of water filtered per net.

Due to electronic problems in May 2010 with the MOCNESS and engine malfunction on the ship in September 2010, no samples were collected at the South and North stations on those cruises, respectively. Further problems with the MOCNESS in May 2011 at the South station led to only 3 successful net tows at that station. For the rest of the stations on each cruise, 6-10 MOCNESS tows were successfully completed. All samples were preserved immediately upon retrieval of the net in a seawater solution with $4 \%$ buffered formaldehyde. Samples were sorted at the lab under stereo dissecting microscopes to enumerate and identify A. tonsa copepodites and adults. In summer 2010, the first 50 zooplankton individuals that were sorted for each net were measured for length and width, and here we report prosome measurements for adult male and female $A$. tonsa. These measurements were used to calculate surface area and volume based on the equations for a prolate spheroid.

Hydrographic data was averaged over $0.5 \mathrm{~m}$ depth bins to characterize the water column using the mean and SD of temperature $\left({ }^{\circ} \mathrm{C}\right)$, salinity, and dissolved oxygen $\left(\mathrm{mg} \mathrm{l}^{-1}\right)$. Oxygen concentration was converted to partial pressure $(\mathrm{kPa})$ by first determining the percent saturation of dissolved oxygen at each temperature and salinity value from the hydrographic data, using equations from Benson \& Krause (1980, 1984). The percent saturation was then multiplied by the partial pressure for $\mathrm{O}_{2}$ at the sea surface $(21.198 \mathrm{kPa})$ to determine the partial pressure of oxygen $\left(p \mathrm{O}_{2} ; \mathrm{kPa}\right)$.

To determine biologically relevant metrics to describe dissolved oxygen habitat for $A$. tonsa, we calculated the values of $P_{\text {crit }}$ and $P_{\text {leth }}$ as described in Elliott et al. (2013a), using the depth profiles of temperature and salinity from the hydrographic casts. In that paper, $P_{\text {crit }}$ and $P_{\text {leth }}$ were determined based on multiple different vital rate measurements for adult female $A$. tonsa made under a variety of low oxygen conditions and converted to respiration rate equivalents to determine the relationship between respiration rate and dissolved oxygen partial pressure. A $Q_{10}$ value for salinity is used that is calculated for 3 specific salinity values (Gaudy et al. 2000), and here we fitted a linear regression through the $Q_{10}$ values and included it in the equations, such that the final equations are:

$$
\begin{aligned}
& P_{\text {crit }}=7.51(0.07 S+0.51)^{0.1(T-18)}+0.59 \\
& P_{\text {leth }}=2.61(0.07 S+0.51)^{0.1(T-18)}+0.59
\end{aligned}
$$

where $T$ is temperature $\left({ }^{\circ} \mathrm{C}\right)$ and $S$ is salinity. To determine the impacts of $\mathrm{pO}_{2}$ on $A$. tonsa vertical distribution, we categorized the water based on the values of $p \mathrm{O}_{2}$ : water that had $p \mathrm{O}_{2}>P_{\text {crit }}$ was considered 'oxic', and water with $P_{\text {leth }}<p \mathrm{O}_{2}<P_{\text {crit }}$ was labelled ' $p \mathrm{O}_{2}<P_{\text {crit }}$ ', and water with $p \mathrm{O}_{2}<P_{\text {leth }}$ was labelled ' $p \mathrm{O}_{2}<P_{\text {leth' }}$. We used the minimum value of $p \mathrm{O}_{2}$ for each MOCNESS tow to categorize the habitat during that tow for our analyses of vertical distribution in relation to dissolved oxygen. The actual lethality of water with $\mathrm{pO}_{2}<P_{\text {leth }}$ is likely determined by the time an organism spends in that water, and thus can be thought of more as potentially lethal than acutely lethal, but water with $\mathrm{pO}_{2}<P_{\text {leth }}$ cannot support basal metabolism.

To estimate the vertical distribution of $A$. tonsa copepodites, adult females, and adult males, we calculated 2 different metrics from each MOCNESS tow. The weighted mean depth (WMD; m) was calculated using the following equation:

$$
\mathrm{WMD}=\sum\left(N_{i} \times Z_{i} \times D_{i}\right) / \sum\left(N_{i} \times Z_{i}\right)
$$

where $D_{i}$ is the center of the depth interval of sample $i(\mathrm{~m}), Z_{i}$ is the thickness of the depth interval (m), and $N_{i}$ is the concentration of individuals in the depth interval $\left(\mathrm{m}^{-3}\right)$. Additionally, we estimated the fraction of individuals that were above and below the pycnocline by dividing the abundance of individuals $\left(\mathrm{m}^{-2}\right)$ in either the surface or bottom layer, respectively, by the total abundance. WMD values were compared among the 3 categories of $\mathrm{pO}_{2}$ for copepodites, adult females, and adult males of $A$. tonsa. Regression tree analysis was conducted to determine whether there were thresholds of temperature and $p \mathrm{O}_{2}$ in the fraction of individuals found either above or below the pycnocline. All statistical and graphical analyses were done in Matlab (version R2015b, Mathworks).

\section{RESULTS}

Oceanographic conditions differed between stations, seasons, and years (Fig. 2). Generally, the North station had lower dissolved oxygen concentration in the bottom and lower salinity throughout the water column than the South station. Temperature patterns were consistent between the stations, with spring having the lowest temperatures and summer the 

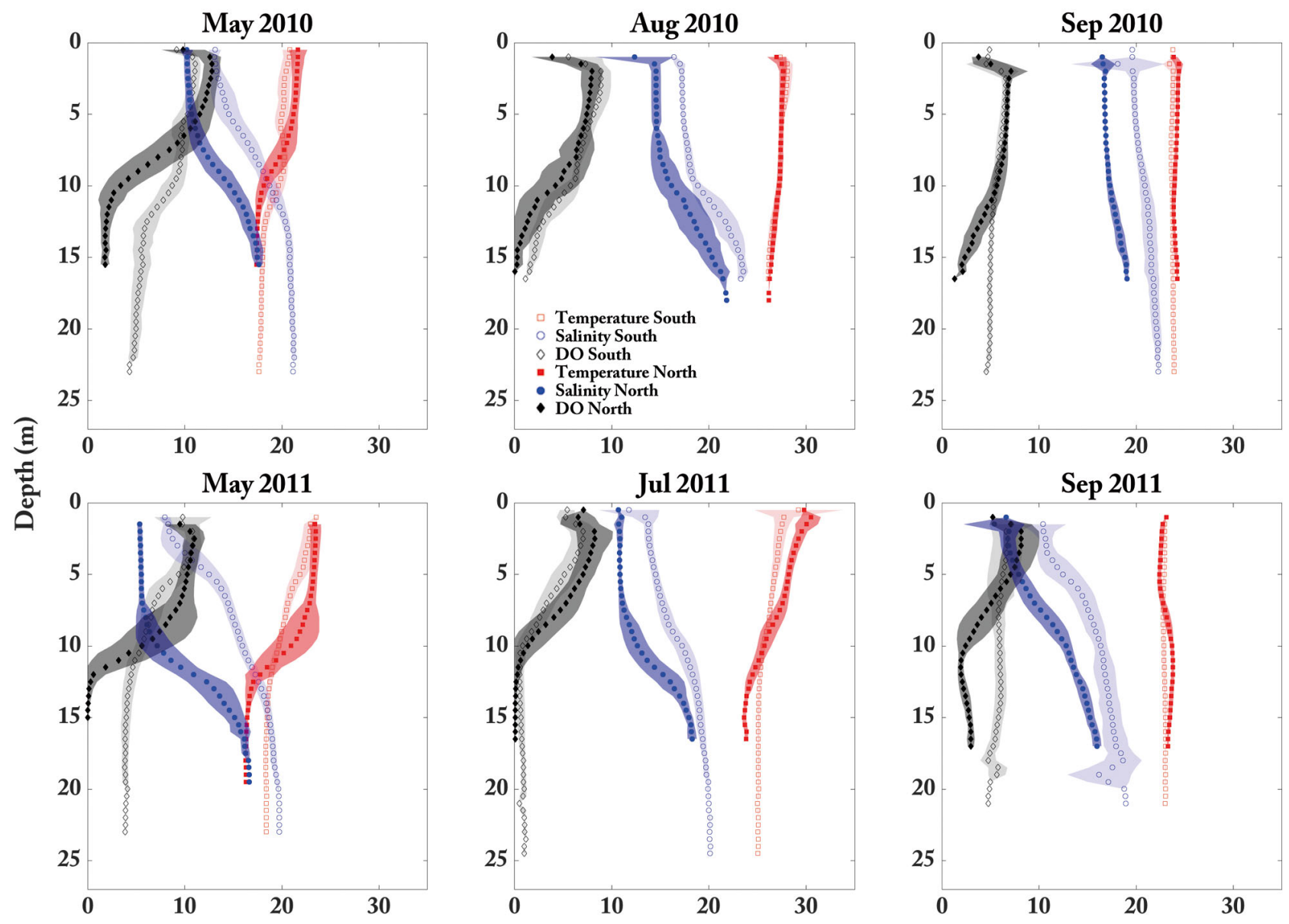

Temperature, salinity, and dissolved oxygen

Fig. 2. CTD profile data from each cruise, with symbols representing data from each station averaged in $0.5 \mathrm{~m}$ depth bins, with shading showing SD at each depth bin. Open symbols show data from the South station, and closed symbols from the North station, for temperature $\left({ }^{\circ} \mathrm{C}\right.$, red square), salinity (PSU, blue circle), and dissolved oxygen (DO) concentration (mg ${ }^{-1}$, black diamond)

warmest. Salinity was generally lowest in spring and highest in summer, and 2011 had overall lower salinity than 2010. Dissolved oxygen concentration was lowest in summer at both stations. Spring dissolved oxygen was always supersaturated above the pycnocline, whereas fall dissolved oxygen was never shown to be supersaturated (data not shown). In summer, near-surface water in the North station in both years and in the South station in 2010 was supersaturated (data not shown).

Applying the calculations for $P_{\text {crit }}$ and $P_{\text {leth }}$ from Elliott et al. (2013a) to the dissolved oxygen and temperature data suggests differences between stations, seasons, and years in the oxygen available to Acartia tonsa (Fig. 3). In general, fully oxygenated water columns were observed only at the South station, and it was observed in spring and autumn of both years. The incidence of $p \mathrm{O}_{2}<P_{\text {leth }}$ occurred more in 2011 than in 2010, occurring at depths $<10 \mathrm{~m}$ at both sta- tions in summer 2011, and at the North station below $12 \mathrm{~m}$ in spring 2011. In contrast, in summer 2010, $p \mathrm{O}_{2}$ $<P_{\text {leth }}$ occurred in water deeper than $12 \mathrm{~m}$ and $16 \mathrm{~m}$ at the North and South stations, respectively, meaning that the fraction of the water column where $\mathrm{pO}_{2}<$ $P_{\text {leth }}$ was greater in summer $2011(42-63 \%)$ than it was in $2010(9-29 \%)$ at both stations (Table 2). In spring and autumn of both years, the South station was fully oxygenated, whereas water with $\mathrm{pO}_{2}<P_{\text {crit }}$ occurred in both years at the North station in spring and autumn, and some incidence of water with $p \mathrm{O}_{2}<$ $P_{\text {leth }}$ was observed in spring at the North station in 2011. Prior to our autumn 2011 cruise, the Chesapeake Bay watershed experienced a series of storm events from Hurricane Irene and Tropical Storm Lee, which caused elevated freshwater input to the Chesapeake Bay. This is reflected in the low salinity and dissolved oxygen in the surface during that cruise, including $p \mathrm{O}_{2}<P_{\text {crit }}$ at the surface. 

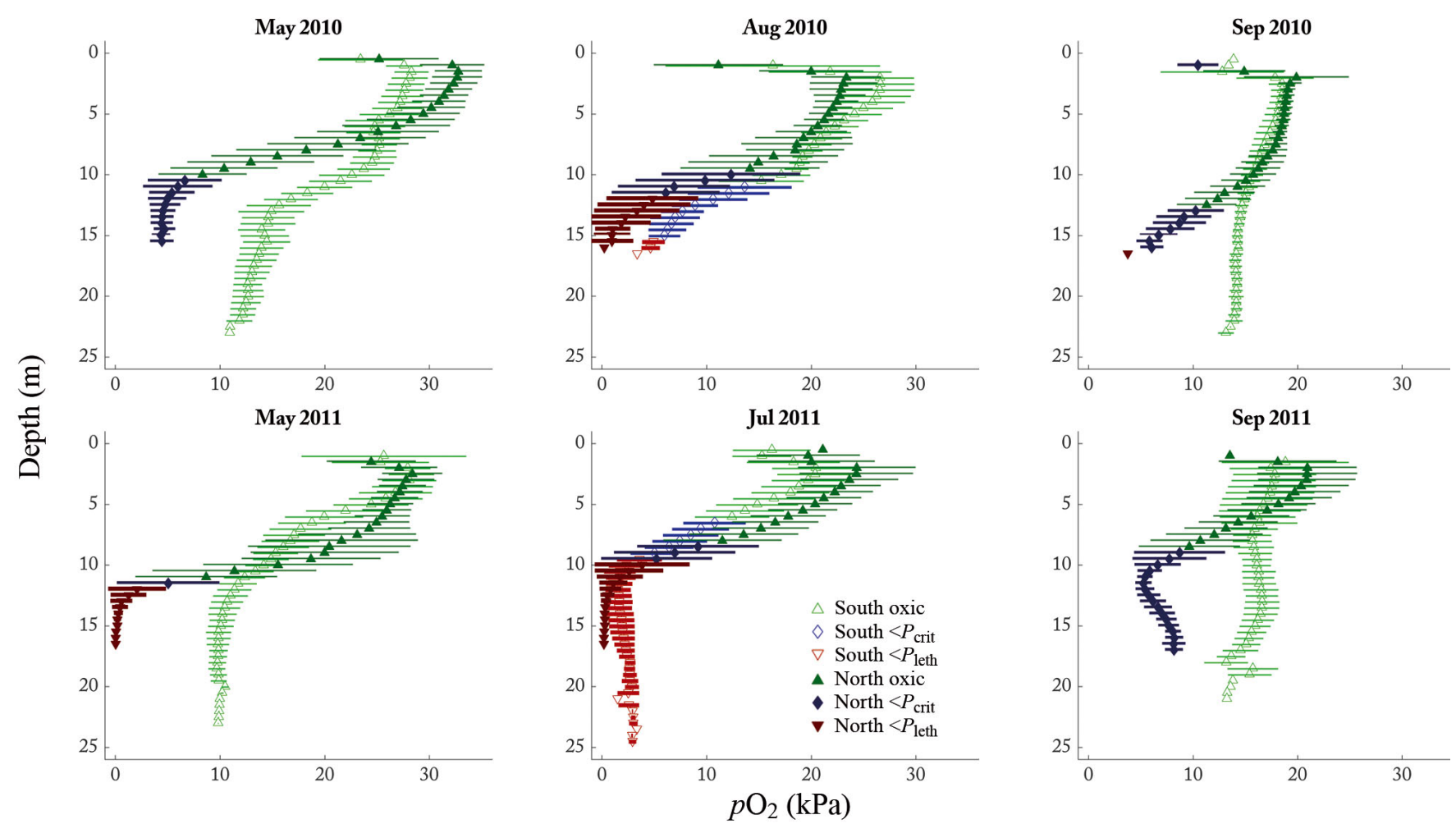

Fig. 3. Dissolved oxygen partial pressure $\left(\mathrm{pO}_{2}\right)$ relative to the critical $\left(P_{\text {crit }}\right)$ and potentially lethal $\left(P_{\text {leth }}\right)$ partial pressure of oxygen for Acartia tonsa from each cruise at each station. Symbols and colors represent mean values from CTD data at $0.5 \mathrm{~m}$ depth bins, lines show SD of the mean at each depth bin. Conditions where $\mathrm{pO}_{2}>P_{\text {crit }}$ (green upward facing triangle, oxic), $P_{\text {crit }}$ $>p \mathrm{O}_{2}>P_{\text {leth }}$ (blue diamond), and $\mathrm{pO}_{2}<P_{\text {leth }}$ (red downward facing triangle) are shown. Filled symbols and darker colors show data from the North station; open symbols and lighter colors show data from the South station

Table 2. Mean fraction of the water column in which the partial pressure of dissolved oxygen $\left(\mathrm{pO}_{2}\right)$ was below the critical $\left(P_{\text {crit }}\right)$ or potentially lethal $\left(P_{\text {leth }}\right)$ partial pressure of oxygen for Acartia tonsa or that was hypoxic $\left(<2 \mathrm{mg} \mathrm{l}^{-1}\right)$, for each station on each cruise

\begin{tabular}{|c|c|c|c|c|}
\hline \multirow[t]{2}{*}{ Start date } & \multirow[t]{2}{*}{ Stn } & \multicolumn{3}{|c|}{ Fraction of water column (\%) } \\
\hline & & $p \mathrm{O}_{2}<P_{\text {crit }}$ & $p \mathrm{O}_{2}<P_{\text {leth }}$ & Hypoxic \\
\hline \multirow[t]{2}{*}{ May 2010} & North & & & \\
\hline & South & 35.5 & & 22.6 \\
\hline \multirow[t]{2}{*}{ Aug 2010} & North & 28.1 & 9.4 & 9.4 \\
\hline & South & 12.9 & 29.0 & 29.0 \\
\hline \multirow[t]{2}{*}{ Sep 2010} & North & & & \\
\hline & South & 25.0 & 3.1 & 3.1 \\
\hline \multirow[t]{2}{*}{ May 2011} & North & & & \\
\hline & South & 3.2 & 32.3 & 32.3 \\
\hline \multirow[t]{2}{*}{ Jul 2011} & North & 12.2 & 63.3 & 65.3 \\
\hline & South & 9.1 & 42.4 & 45.5 \\
\hline \multirow[t]{2}{*}{ Sep 2011} & North & & & \\
\hline & South & 51.5 & & 9.1 \\
\hline
\end{tabular}

Mean $( \pm \mathrm{SD})$ sampling depth at the North station was shallower $(15.9 \pm 2.0 \mathrm{~m})$ than at the South station $(17.4 \pm 6.2 \mathrm{~m})$, so we are reporting concentration $\left(\mathrm{m}^{-3}\right)$ and not abundance $\left(\mathrm{m}^{-2}\right)$ data to describe the differences between stations and cruises for the amount of copepods in the total water column (Fig. 4). Patterns were consistent between both metrics (data not shown). Copepods were most concentrated in the North station in spring 2010 (there is no data from the South station in spring 2010), and also at the North station in spring of 2011 (Fig. 4). In summer 2010, concentration was higher at the South station, but in summer 2011, the concentration was higher at the North station. In autumn of 2011, abundance was higher at the South station, but there is no data for the North station in 2010. Measurements of adult females and males in summer 2010 showed that males were smaller than females, as we expected, and males also had a larger surface:volume ratio (Table 3). Individuals at the South station were somewhat shorter than individuals at the North station.

Overall patterns of DVM, as estimated using WMD (m) calculated for each MOCNESS tow, varied between dissolved oxygen conditions (Fig. 5, Fig. S1 in the Supplement at www.int-res.com/articles/suppl/ m575p057_supp.pdf). In general, the migration amplitude, or the difference between day and night WMD, 


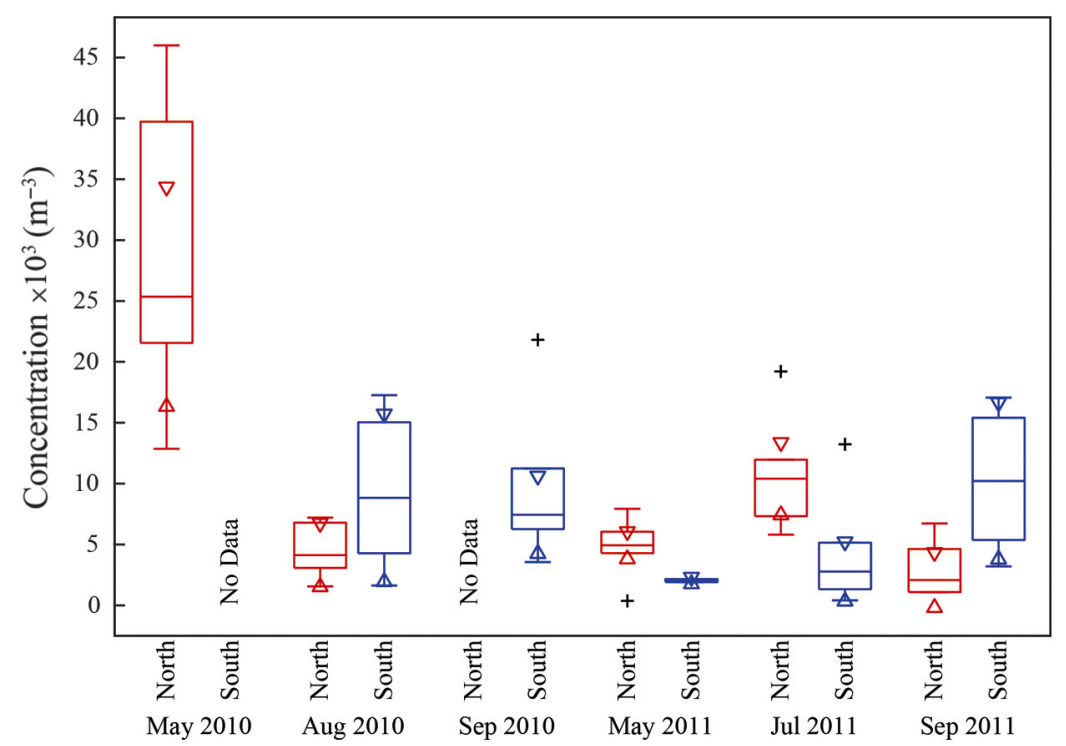

Fig. 4. Concentration of Acartia tonsa copepodites and adults integrated over entire depth range sampled from MOCNESS tows at each station on each cruise. Boxes show interquartile range, horizontal lines show median, triangle symbols show $95 \%$ CI of the median, whiskers show $\pm 2.7 \mathrm{SD}$ of the data and ' + ' symbols show outliers. Data from North station are in red and South station in blue. No data available from MOCNESS tows from South station in May 2010 or North station in September 2010

was greatest under conditions with $\mathrm{pO}_{2}<P_{\text {crit, }}$ and was lowest for conditions with $p \mathrm{O}_{2}<P_{\text {leth. }}$ For both deoxygenation conditions $\left(\mathrm{O}_{2}<P_{\text {crit }}\right.$ and $\left.p \mathrm{O}_{2}<P_{\text {leth }}\right)$, the direction of migration was that of canonical DVM, in which individuals were observed at shallower depths at night than during the day. Under oxic conditions, the pattern observed was that of reverse DVM, where more individuals were found at shallower depths during the day.

The fraction of individuals above and below the pycnocline in relation to temperature and $p \mathrm{O}_{2}$ showed some general patterns across developmental stages (Fig. 6). Adult females were generally more abundant above the pycnocline than both adult males and copepodites, particularly at lower temperatures. A higher fraction of adult males were found below the pycnocline with cooler temperatures and lower dissolved oxygen, compared to both copepodites and adult females. Regression tree analysis was used to determine breakpoints in the fraction of copepodites, adult females, and adult males predicted by temperature and $p \mathrm{O}_{2}$ (Fig. 7, Table S1 in the Supplement). Values of $p \mathrm{O}_{2}$ $1.2-2.0 \mathrm{kPa}$ were the primary break points (i.e. the first node predicted) for the fraction above the pycnocline for each stage, and for the fraction below the pycnocline for copepodites and adult females. In all of these cases when $p \mathrm{O}_{2}<1.2-2.0 \mathrm{kPa}$, the mean fraction of animals above the pycnocline was $>0.65$ and the mean fraction of animals below the pycnocline was 0.01 . The lowest fraction of individuals found above the pycnocline occurred at low temperatures and moderate $p \mathrm{O}_{2}$ values. For the fraction of males below the pycnocline, the primary breakpoint was a temperature of $23.7^{\circ} \mathrm{C}$, and below that temperature, a higher fraction of the male population ( $>0.12$ ) was found at all $p \mathrm{O}_{2}$ values compared to above that temperature (0.01). For males below the pycnocline, the highest fraction was found at cooler temperatures and higher $\mathrm{pO}_{2}(0.42$ at $>4.8 \mathrm{kPa})$.

\section{DISCUSSION}

The goal of this project was to determine the combined effects of temperature and dissolved oxygen on Acartia tonsa vertical distribution in the Chesapeake Bay, and our findings show that there are differences in the response to these stressors between adult males and females. Our cruises encompassed a variety of dissolved oxygen and temperature conditions, and our stations provided a contrast among conditions within a season, all of which provided a gradient of sampling conditions that allowed us to examine the effects on A. tonsa vertical distribution. As expected,

Table 3. Mean sizes $( \pm \mathrm{SD})$ of Acartia tonsa males and females at North and South stations in summer 2010. S:V is surface: volume ratio

\begin{tabular}{|c|c|c|c|c|c|c|c|}
\hline Stn & Sex & $\mathrm{N}$ & Prosome length (mm) & Prosome width (mm) & Volume $\left(\mathrm{mm}^{3}\right)$ & Surface area $\left(\mathrm{mm}^{2}\right)$ & $\mathrm{S}: \mathrm{V}$ \\
\hline \multirow[t]{2}{*}{ North } & $\mathrm{F}$ & 207 & $0.819(0.047)$ & $0.261(0.023)$ & 0.029 & 0.549 & 18.8 \\
\hline & M & 303 & $0.665(0.028)$ & $0.224(0.020)$ & 0.017 & 0.383 & 22.0 \\
\hline \multirow[t]{2}{*}{ South } & $\mathrm{F}$ & 240 & $0.744(0.069)$ & $0.239(0.027)$ & 0.022 & 0.457 & 20.5 \\
\hline & M & 267 & $0.635(0.032)$ & $0.214(0.021)$ & 0.015 & 0.350 & 23.0 \\
\hline
\end{tabular}




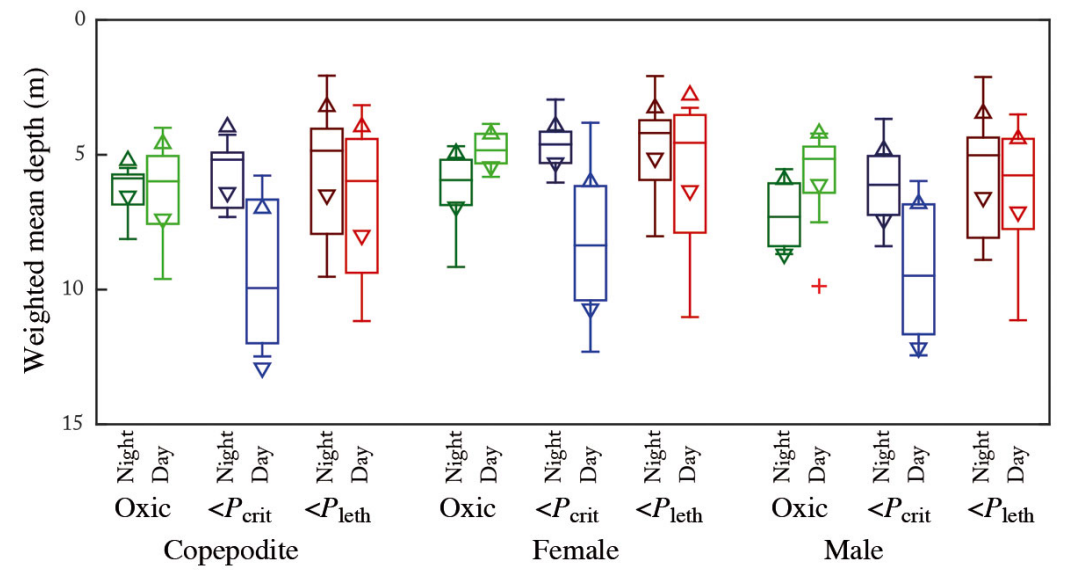

Fig. 5. Weighted mean depth of copepodite, adult female, and adult male Acartia tonsa collected during day and night tows under different minimum dissolved oxygen partial pressure $\left(\mathrm{pO}_{2}\right)$ conditions relative to the critical $\left(P_{\text {crit }}\right)$ and potentially lethal $\left(P_{\text {leth }}\right)$ partial pressure of oxygen for $A$. tonsa. Boxes show interquartile range, horizontal lines show median, triangle symbols show $95 \%$ $\mathrm{CI}$ of the median, whiskers show $\pm 2.7 \mathrm{SD}$ of the data, and ' + ' symbols show outliers. Conditions where $p \mathrm{O}_{2}>P_{\text {crit }}$ (green boxes and lines, oxic), $P_{\text {crit }}>p \mathrm{O}_{2}>$ $P_{\text {leth }}$ (blue boxes and lines), and $p \mathrm{O}_{2}<P_{\text {leth }}$ (red boxes and lines) are shown. Darker colors show data collected at night, lighter colors during the day

our northern station experienced lower dissolved oxygen conditions than the southern station, and the lowest dissolved oxygen concentrations occurred in summer when water temperature was highest.
A number of patterns emerged among copepodite, adult female, and adult male $A$. tonsa over the range of conditions we experienced. The DVM behavior of $A$. tonsa changed in response to the categories of dissolved oxygen condition. When potentially lethal conditions $\left(p \mathrm{O}_{2}<P_{\text {leth }}\right)$ were found in bottom water, the extent of vertical migration was truncated, as evidenced by WMD remaining shallow both day and night. The largest migration amplitude was shown under critical conditions $\left(P_{\text {crit }}>p \mathrm{O}_{2}>P_{\text {leth }}\right)$. Copepodites, adult females, and adult males exhibited canonical DVM behavior, with higher concentrations observed in shallower depths at night. Under oxic conditions, which occurred at the South station in May and September, the DVM pattern was reversed for adults and the amplitude was smaller than under critical conditions.
Vertical migration behavior of $A$. tonsa has been shown to vary with dissolved oxygen concentration, with most cases indicating avoidance of deoxygenated water (Roman et al. 1993, Keister et al. 2000,
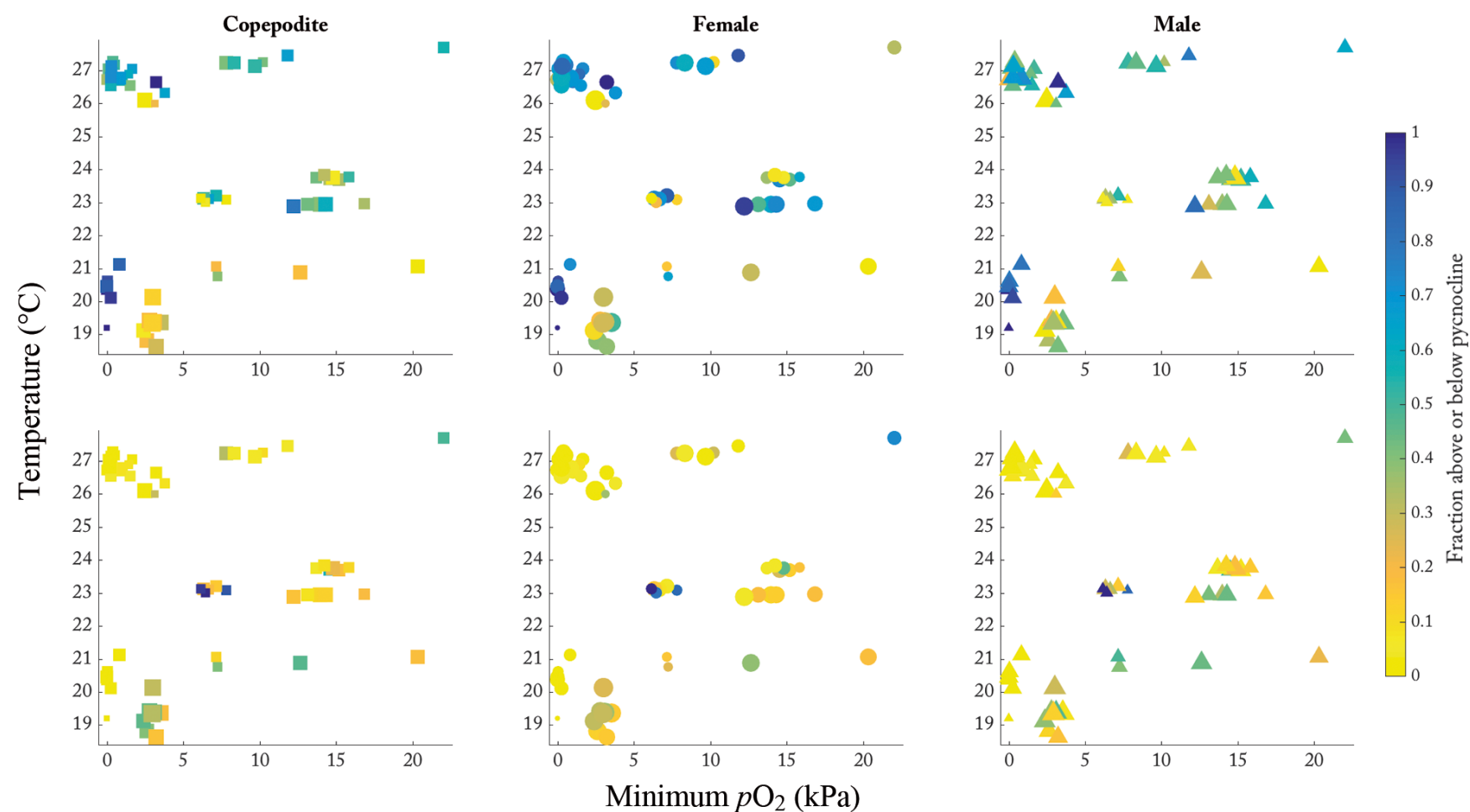

Fig. 6. Scatter plot of mean temperature and minimum partial pressure of dissolved oxygen $\left(p \mathrm{O}_{2}\right)$ from each MOCNESS tow, with symbol size scaled to total abundance of Acartia tonsa for each stage, and colors representing the fraction of copepodites (square), adult females (circle) and adult males (triangle) found above (upper panels) or below (lower panels) the pycnocline 

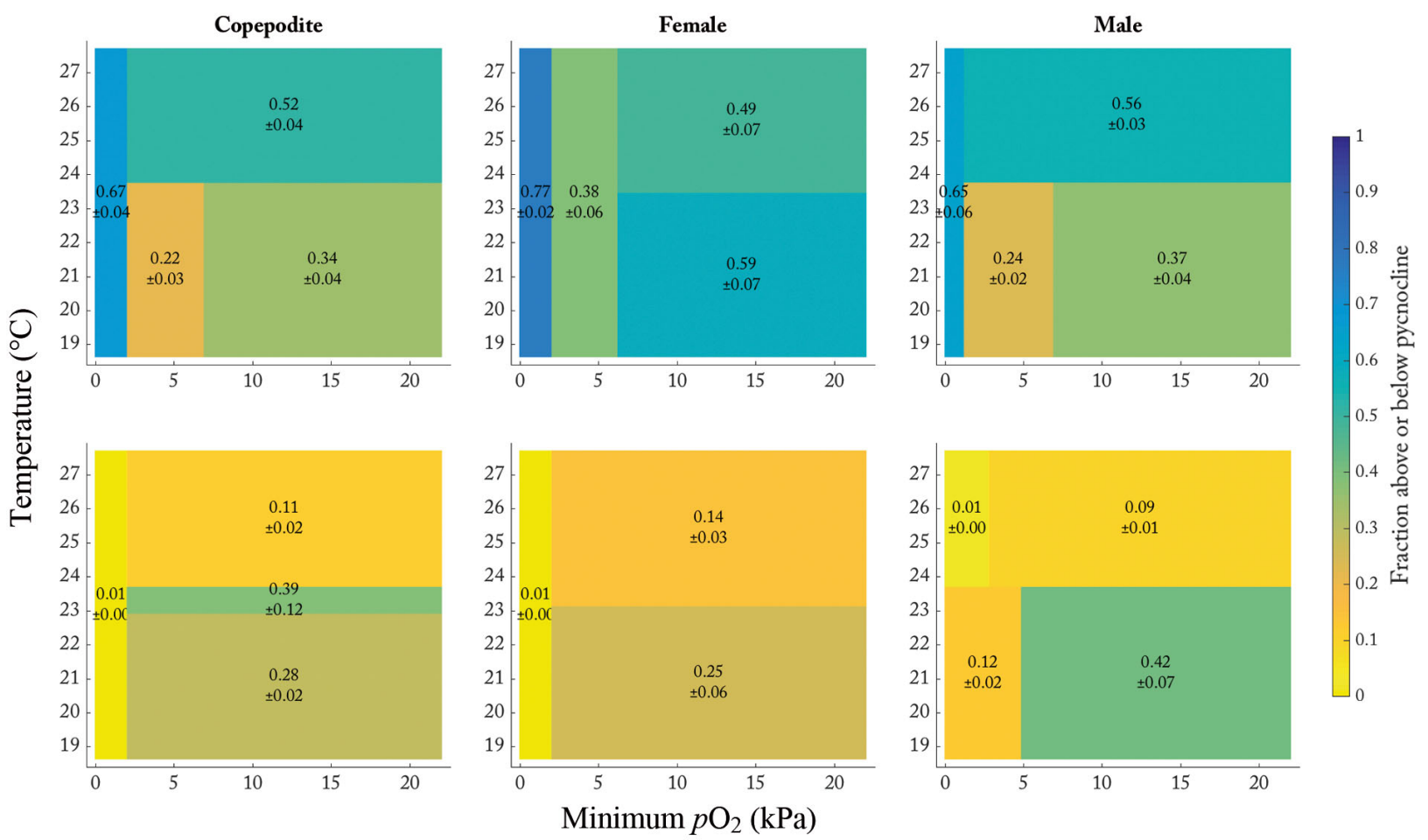

Fig. 7. Regression tree results from analysis of data shown in Fig. 6, with temperature and minimum dissolved oxygen partial pressure $\left(\mathrm{pO}_{2}\right)$ as independent variables, and the fraction of Acartia tonsa copepodites, adult females, and adult males found above (upper panels) or below (lower panels) the pycnocline as dependent variable. Each patch represents a leaf from the regression tree. Colors are scaled to the mean fraction above or below the pycnocline, with the value shown in each leaf region. Minimum leaf size was $\mathrm{n}=12$

North \& Houde 2004, Pierson et al. 2009, Kimmel et al. 2010). Under some conditions, copepods have been shown to occupy deoxygenated water (Keister \& Tuttle 2013), particularly in the presence of predators (Taylor et al. 2007). Reverse DVM has been attributed to the presence of invertebrate predators that do not rely on vision (and thus light) to find their prey (Ohman et al. 1983). In the Chesapeake Bay, those predators could be gelatinous zooplankton (e.g. Chrysaora quinquecirrha or Mnemiopsis leidyi). However, the reverse DVM pattern that we observed during oxic conditions occurred in both seasons where we encountered fully oxic water columns (data not shown), including periods with few predators (spring) and with many predators (autumn).

Using a regression tree analysis, our findings suggested that dissolved oxygen is generally the primary driver of vertical distribution for $A$. tonsa copepodites and females, which are found predominantly in the surface mixed layers when dissolved oxygen is low. In conditions with greater dissolved oxygen, temperature affects vertical distribution, such that a greater fraction of females and copepodites are found below the surface mixed layer. For males, temperature is the primary determinant of vertical distribution at low dissolved oxygen, with a higher fraction of males found below the surface mixed layer when dissolved oxygen and temperature are both low, when compared with both females and copepodites. This suggests different physiological responses to the dual stressors of temperature and oxygen between the sexes, potentially in response to different energetic demands between males and females or reproduction behaviors (Burrows \& Tarling 2004, Kessler 2004). Specifically, oxygen demand and respiration rate have been shown to increase for reproductively active female copepods (Svetlichny et al. 2012, Castellani \& Altunbas 2014), which may require females to reside in shallower and more oxygenated water. In addition, the behavior which drives them to reside in surface waters where they release their eggs at night (White \& Roman 1992) would serve to maximize the probability that they hatch before reaching hypoxic bottom waters. Males and females of one species of deep-sea copepods were shown to have no difference in oxygen consumption or citrate synthase, both markers for aerobic activity, while males had increased activity of lactate dehydrogenase (LDH), a marker of anaerobic activity (Thuesen et al. 1998). Increased LDH activity may indicate either more re- 
liance on burst swimming activity or an adaptation to lower oxygen conditions, but it has been shown to have higher activity in copepods found in or migrating through deoxygenated conditions (Teuber et al. 2013, Cass \& Daly 2015), and it may provide another metric useful in future studies as a means to assess responses to deoxygenation beyond oxygen consumption.

Size has also been shown to affect migration behaviors, with larger animals delaying migration in euphausiids (De Robertis et al. 2000, De Robertis 2002). Adult male A. tonsa are approximately $10 \%$ shorter than females in the Chesapeake Bay (Chen 2009), which may affect vertical distribution or behavior. Male A. tonsa have a higher surface:volume ratio as compared to females, and without gills, copepods must obtain oxygen through pores distributed over their body surface. Thus, male $A$. tonsa may be more efficient at taking up oxygen at low concentrations as compared to females and thus are more tolerant of hypoxic waters. Our copepodite data was not differentiated by individual stage, and thus we cannot assess whether migration behaviors or distribution differed among those stages.

Differences in observed distributions of female, male, and copepodite stages of $A$. tonsa from predictions of available habitat using critical and lethal partial pressure of dissolved oxygen developed by Elliott et al. (2013a) must be interpreted with caution. The Elliott et al. (2013a) analysis was for female $A$. tonsa, which we assumed would predict the oxygen constraints for smaller males and copepodite stages with higher surface:volume ratios and metabolic demands.

A more realistic analysis of available habitat for these other stages would be to develop stage-specific critical and lethal partial pressure of dissolved oxygen. This should be done with future lab measurements with the goal of scaling $P_{\text {crit }}$ and $P_{\text {leth }}$ to copepod mass. Here we also did not address other factors that have been shown to drive vertical migration, including prey availability and predators (e.g. Pearre 2003), both of which are known to vary seasonally in the Chesapeake Bay (e.g. Kemp et al. 2005) and may have impacted vertical distribution in ways we were unable to measure with our methodology. Indeed, predation has been shown to affect copepod vertical migration in a variety of ways (Ohman et al. 1983, Bollens \& Frost 1989, Irigoien et al. 2004). Generally during our study, gelatinous predators, especially the ctenophore $M$. leidyi, were more abundant in 2011, in the summer, and at the North station (K. L. Slater unpubl.), whereas anchovy were found in higher abundances where deoxygenation was less severe, and were more abundant in 2010 (E. D. Houde unpubl.). However, the observed reverse DVM pattern occurred in both seasons where we encountered fully oxic water columns, and we did not observe any obvious trends between vertical migration behavior and predators.

Our use of the partial pressure of dissolved oxygen $(\mathrm{kPa})$ as a predictor of vertical distribution for $A$. tonsa instead of the concentration of dissolved oxygen $\left(\mathrm{mg} \mathrm{l}^{-1}\right)$ has not been done previously in this system and with this taxon. The former metric incorporates the temperature effect on the solubility of dissolved oxygen and thus provides a better estimate of the supply of oxygen for the individuals (e.g. Deutsch et al. 2015), and it has been used extensively in estimating critical and lethal oxygen conditions in animals in oxygen minimum zones (Childress \& Seibel 1998, 2011, Seibel et al. 2016). We then calculated the critical and lethal partial pressure of dissolved oxygen for $A$. tonsa using the equations from Elliott et al. (2013a) to estimate thresholds that may describe the habitat available to A. tonsa. We found some instances of critical and potentially lethal conditions in each season, though lethal conditions were observed with less frequency during autumn than during any other season. In general more potentially lethal conditions were observed in 2011, consistent with the observed correlation between hypoxic volume and streamflow in the Chesapeake Bay (Hagy et al. 2004, Kemp et al. 2005, Murphy et al. 2011).

How the observed sex-specific vertical migration responses to temperature and dissolved oxygen that we observed for $A$. tonsa would lead to changes in population and trophic dynamics has not yet been elucidated. But here we have shown a more complete understanding of how different developmental stages and sexes are affected by habitat conditions in this system. With predicted increases in water temperature ranging from $2-5^{\circ} \mathrm{C}$ for this region (Najjar et al. 2000, 2010), dissolved oxygen demand by A. tonsa is expected to increase, though predictions of bottom water oxygen are less clear. Trends suggest an earlier onset of hypoxia (Murphy et al. 2011), but how that timing interacts with temperature and the phenology of $A$. tonsa in this system is yet unknown. The synergistic effects of changing temperature and deoxygenated water will affect the habitat of $A$. tonsa, and our findings help elucidate the specific responses of A. tonsa vertical distribution and migration under a variety of conditions experienced in the Chesapeake Bay and other coastal and estuarine systems. 
Acknowledgements. We thank the crew of the RV 'Hugh R. Sharp' for their professionalism and hard work. Special thanks to Ginger Jahn, Aidan Fisher, Ford Van Fossen, Catherine Fitzgerald, and Alison Barba. This work was funded by the National Science Foundation, Grant OCE 0961942. This is UMCES contribution 5368.

\section{LITERATURE CITED}

Benson BB, Krause D (1980) The concentration and isotopic fractionation of gases dissolved in freshwater in equilibrium with the atmosphere. 1. Oxygen. Limnol Oceanogr 25:662-671

Benson BB, Krause D (1984) The concentration and isotopic fractionation of oxygen dissolved in freshwater and seawater in equilibrium with the atmosphere. Limnol Oceanogr 29:620-632

Bollens SM, Frost BW (1989) Zooplanktivorous fish and variable diel vertical migration in the marine planktonic copepod Calanus pacificus. Limnol Oceanogr 34: 1072-1083

Burrows MT, Tarling G (2004) Effects of density dependence on diel vertical migration of populations of northern krill: a genetic algorithm model. Mar Ecol Prog Ser 277: 209-220

* Cass CJ, Daly KL (2015) Ecological characteristics of eucalanoid copepods of the eastern tropical North Pacific Ocean: adaptations for life within a low oxygen system. J Exp Mar Biol Ecol 468:118-129

Castellani C, Altunbas Y (2014) Seasonal change in acclimatised respiration rate of Temora longicornis. Mar Ecol Prog Ser 500:83-101

Chen G (2009) Cryptic diversity, ecological differentiation and population genetics of an estuarine copepod, Acartia tonsa Dana 1849 (Copepoda: Calanoida). PhD dissertation, University of Maryland, College Park, MD

Childress JJ, Seibel BA (1998) Life at stable low oxygen levels: adaptations of animals to oceanic oxygen minimum layers. J Exp Biol 201:1223-1232

* Coutant CC (1985) Striped bass, temperature, and dissolved oxygen: a speculative hypothesis for environmental risk. Trans Am Fish Soc 114:31-61

De Robertis A (2002) Small-scale spatial distribution of the euphausiid Euphausia pacifica and overlap with planktivorous fishes. J Plankton Res 24:1207-1220

* De Robertis A, Jaffe JS, Ohman MD (2000) Size-dependent visual predation risk and the timing of vertical migration in zooplankton. Limnol Oceanogr 45:1838-1844

* Decker MB, Breitburg DL, Marcus NH (2003) Geographical differences in behavioral responses to hypoxia: local adaptation to an anthropogenic stressor? Ecol Appl 13:1104-1109

Deutsch C, Ferrel A, Seibel B, Pörtner HO, Huey RB (2015) Climate change tightens a metabolic constraint on marine habitats. Science 348:1132-1135

Diaz RJ, Rosenberg R (2008) Spreading dead zones and consequences for marine ecosystems. Science 321:926-929

Elder LE, Seibel BA (2015) Ecophysiological implications of vertical migration into oxygen minimum zones for the hyperiid amphipod Phronima sedentaria. J Plankton Res 37:897-911

Elliott DT, Pierson JJ, Roman MR (2013a) Copepods and hypoxia in Chesapeake Bay: abundance, vertical position and non-predatory mortality. J Plankton Res 35 : 1027-1034
Elliott DT, Pierson JJ, Roman MR (2013b) Predicting the effects of coastal hypoxia on vital rates of the planktonic copepod Acartia tonsa Dana. PLOS ONE 8:e63987

*Gaudy R, Cervetto G, Pagano M (2000) Comparison of the metabolism of Acartia clausi and A. tonsa: influence of temperature and salinity. J Exp Mar Biol Ecol 247: $51-65$

*Hagy JD, Boynton WR, Keefe CW, Wood KV (2004) Hypoxia in Chesapeake Bay, 1950-2001: long-term change in relation to nutrient loading and river flow. Estuaries 27: $634-658$

* Irigoien X, Conway DV, Harris RP (2004) Flexible diel vertical migration behaviour of zooplankton in the Irish Sea. Mar Ecol Prog Ser 267:85-97

Keister JE, Tuttle LB (2013) Effects of bottom-layer hypoxia on spatial distributions and community structure of mesozooplankton in a sub-estuary of Puget Sound, Washington, USA. Limnol Oceanogr 58:667-680

Keister JE, Houde ED, Breitburg DL (2000) Effects of bottom-layer hypoxia on abundances and depth distributions of organisms in Patuxent River, Chesapeake Bay. Mar Ecol Prog Ser 205:43-59

Kemp WM, Boynton WR, Adolf JE, Boesch DF and others (2005) Eutrophication of Chesapeake Bay: historical trends and ecological interactions. Mar Ecol Prog Ser 303:1-29

Kessler K (2004) Distribution of Daphnia in a trade-off between food and temperature: individual habitat choice and time allocation. Freshw Biol 49:1220-1229

* Kimmel DG, Boicourt WC, Pierson JJ, Roman MR, Zhang X (2010) The vertical distribution and diel variability of mesozooplankton biomass, abundance and size in response to hypoxia in the northern Gulf of Mexico USA. J Plankton Res 32:1185-1202

Mauchline J (1998) The biology of calanoid copepods. Academic Press, London

* Murphy RR, Kemp WM, Ball WP (2011) Long-term trends in Chesapeake Bay seasonal hypoxia, stratification, and nutrient loading. Estuar Coasts 34:1293-1309

Najjar RG, Walker HA, Anderson PJ, Barron EJ and others (2000) The potential impacts of climate change on the mid-Atlantic coastal region. Clim Res 14:219-233

Najjar RG, Pyke CR, Adams MB, Breitburg D and others (2010) Potential climate-change impacts on the Chesapeake Bay. Estuar Coast Shelf Sci 86:1-20

North E, Houde E (2004) Distribution and transport of bay anchovy (Anchoa mitchilli) eggs and larvae in Chesapeake Bay. Estuar Coast Shelf Sci 60:409-429

* Ohman MD, Frost BW, Cohen EB (1983) Reverse diel vertical migration: an escape from invertebrate predators. Science 220:1404-1407

Olson MM (1987) Zooplankton. In: Heck KL (ed) Ecological studies in the middle reach of the Chesapeake Bay. Springer, New York, NY, p 38-81

* Pearre S (2003) Eat and run? The hunger/satiation hypothesis in vertical migration: history, evidence and consequences. Biol Rev Camb Philos Soc 78:1-79

* Pierson JJ, Roman MR, Kimmel DG, Boicourt WC, Zhang X (2009) Quantifying changes in the vertical distribution of mesozooplankton in response to hypoxic bottom waters. J Exp Mar Biol Ecol 381:S74-S79

Pörtner HO (2010) Oxygen- and capacity-limitation of thermal tolerance: a matrix for integrating climate-related stressor effects in marine ecosystems. J Exp Biol 213: 881-893 
Preston BL (2004) Observed winter warming of the Chesapeake Bay estuary (1949-2002): implications for ecosystem management. Environ Manage 34:125-139

Rhein M, Rintoul SR, Aoki S, Campos E and others (2013) Observations: ocean. In: Stocker TF, Qin D, Plattner GK, Tignor M and others (eds) Climate change 2013: the physical science basis. Contribution of Working Group I to the Fifth Assessment Report of the Intergovernmental Panel on Climate Change. Cambridge University Press, Cambridge, p 255-316

Roman MR, Gauzens AL, Rhinehart WK, White JR (1993) Effects of low oxygen waters on Chesapeake Bay zooplankton. Limnol Oceanogr 38:1603-1614

Sedlacek C, Marcus NH (2005) Egg production of the copepod Acartia tonsa: the influence of hypoxia and food concentration. J Exp Mar Biol Ecol 318:183-190

Seibel BA (2011) Critical oxygen levels and metabolic suppression in oceanic oxygen minimum zones. J Exp Biol 214:326-336

Seibel BA (2015) Environmental physiology of the jumbo squid, Dosidicus gigas (d'Orbigny, 1835) (Cephalopoda: Ommastrephidae): implications for changing climate. Am Malacol Bull 33:161-173

Seibel BA, Schneider JL, Kaartvedt S, Wishner KF, Daly KL (2016) Hypoxia tolerance and metabolic suppression in oxygen minimum zone euphausiids: implications for ocean deoxygenation and biogeochemical cycles. Integr Comp Biol 56:510-523

Stalder L, Marcus N (1997) Zooplankton responses to

Editorial responsibility: Sigrun Jónasdóttir,

Charlottenlund, Denmark hypoxia: behavioral patterns and survival of three species of calanoid copepods. Mar Biol 127:599-607

Svetlichny L, Khanaychenko A, Hubareva E, Aganesova L (2012) Partitioning of respiratory energy and environmental tolerance in the copepods Calanipeda aquaedulcis and Arctodiaptomus salinus. Estuar Coast Shelf Sci 114:199-207

Taylor JC, Rand PS (2003) Spatial overlap and distribution of anchovies (Anchoa spp.) and copepods in a shallow stratified estuary. Aquat Living Resour 16:191-196

Taylor JC, Rand PS, Jenkins J (2007) Swimming behavior of juvenile anchovies (Anchoa spp.) in an episodically hypoxic estuary: implications for individual energetics and trophic dynamics. Mar Biol 152:939-957

*Teuber L, Schukat A, Hagen W, Auel H (2013) Distribution and ecophysiology of calanoid copepods in relation to the oxygen minimum zone in the eastern tropical Atlantic. PLOS ONE 8:e77590

* Thuesen EV, Miller CB, Childress JJ (1998) Ecophysiological interpretation of oxygen consumption rates and enzymatic activities of deep-sea copepods. Mar Ecol Prog Ser 168:95-107

White JR, Roman MR (1992) Egg production by the calanoid copepod Arcartia tonsa in the mesohaline Chesapeake Bay: the importance of food resources and temperature. Mar Ecol Prog Ser 86:239-249

*Wiebe PH, Allison D, Kennedy M, Moncoiffe G (2015) A vocabulary for the configuration of net tows for collecting plankton and micronekton. J Plankton Res 37:21-27

Submitted: December 20, 2016; Accepted: May 19, 2017 Proofs received from author(s): June 28, 2017 